\title{
Diffuse alveolar damage in a patient treated with gemcitabine
}

\author{
A. Marruchella*, G. Fiorenzano*, A. Merizzi*, G. Rossi*, P.L. Chiodera**
}

\begin{abstract}
Diffuse alveolar damage in a patient treated with gemcitabine. A. Marruchella, G. Fiorenzano, A. Merizzi, G. Rossi, P.L. Chiodera. CERS Journals Ltd 1998.

ABSTRACT: We present a case of diffuse alveolar damage (DAD) that occurred in a male aged 68 yrs treated with gemcitabine, a novel antineoplastic agent, that was given for hepatic relapse of a previously resected non-small cell lung cancer.

The patient developed acute respiratory failure after the sixth drug dose, and died 4 days after admission. Autopsy revealed a pattern of DAD. No evidence of infection or other specific aetiologies could be found. To our knowledge, only three cases of pulmonary toxicity resulting from treatment with gemcitabine have been published; two of them were fatal and postmortem examination revealed a pattern consistent with acute respiratory distress syndrome. A careful survey may determine the incidence of pulmonary toxicity of this new drug in the future.
\end{abstract} Eur Respir J 1998; 11: 504-506.

\author{
*Divisione di Broncopneumologia, Ospedale \\ "E. Morelli", Sondalo, Italy. ** Servizio di \\ Anatomia Patologica, Casa di cura S. Anna, \\ Brescia, Italy. \\ Correspondence: A. Marruchella, Divisione \\ di Broncopneumologia, Ospedale "E. Morelli", \\ 23039 Sondalo, Italy, Fax: 39342802146
}

Keywords: Acute interstitial pneumonia, antineoplastic agents, chemotherapy, diffuse alveolar damage, gemcitabine

Received: June 171997

Accepted after revision October 251997
Diffuse alveolar damage (DAD) is a descriptive term for the pathological findings following acute lung injury of several causes [1]. Many causes have been related to DAD: infectious agents, inhalants, connective tissue disease, drugs, shock, sepsis and radiation [1]. In the acute phase, there is oedema, epithelial necrosis and fibrinous exudate in alveolar spaces, with hyaline membrane formation. As the process organizes (organizing DAD), alveolar walls are lined by proliferating type II cells, there is a fibroblastic proliferation in the interstitium and airspaces, while hyaline membranes may be completely reabsorbed [1].

Acute interstitial pneumonia (AIP) is the pathological correlate of Hamman-Rich syndrome [1-3] and exhibits the changes described as organizing DAD.

We describe a case of DAD that occurred in a patient treated with gemcitabine, a novel chemotherapeutic agent that is structurally related to cytosine arabinoside, which is active against non-small cell lung cancer (NSCLC) $[4,5]$.

\section{Case report}

A 68 yr old man had undergone a left pneumonectomy for squamous cell lung cancer (tumour, node, metastasis (TNM) classification $\mathrm{pT}_{2} \mathrm{~N}_{1} \mathrm{M}_{0}$, stage II) in June 1994. No other antineoplastic therapies had been administered. Because of hepatic metastases in July 1996, chemotherapy with gemcitabine was started $\left(1,250 \mathrm{mg} \cdot \mathrm{m}^{-2}\right.$, as a $30 \mathrm{~min}$ infusion once weekly for 3 weeks followed by a week of rest) [3]. Concomitant therapy included $12.5 \mathrm{mg}$ of prednisone daily.

Six days after the sixth dose of gemcitabine (September 1996), the patient was admitted to hospital, because of mild fever, malaise, nonproductive cough and progressive dyspnoea. At physical examination there was cyanosis, and crackles were audible over the right lung field. Respiratory frequency was 24 breaths. $\mathrm{min}^{-1}$; cardiac frequency 110 beats $\cdot \mathrm{min}^{-1}$; arterial blood pressure $120 / 80 \mathrm{mmHg}$. No clinical conditions known to be risk factors for acute respiratory distress syndrome (ARDS) were present [6]. Chest radiography showed left pneumonectomy and a right basilar shadow (fig. 1). Arterial blood gases revealed moderate hypoxaemia (arterial oxygen tension $\left(\mathrm{Pa}_{\mathrm{a}} \mathrm{O}_{2}\right)=7.0 \mathrm{kPa}(53$ $\mathrm{mmHg})$ ) corrected with $\mathrm{O}_{2} 2 \mathrm{~L} \cdot \mathrm{min}^{-1}\left(\mathrm{~Pa}_{\mathrm{a}, \mathrm{O}_{2}}=9.2 \mathrm{kPa}(69\right.$ $\mathrm{mmHg}$ )), and respiratory alkalosis (arterial carbon dioxide tension $\left.\left(P \mathrm{a}, \mathrm{CO}_{2}\right)=2.9 \mathrm{kPa}(22 \mathrm{mmHg}) ; \mathrm{pH}=7.55\right)$. Laboratory tests did not show relevant abnormalities: white blood

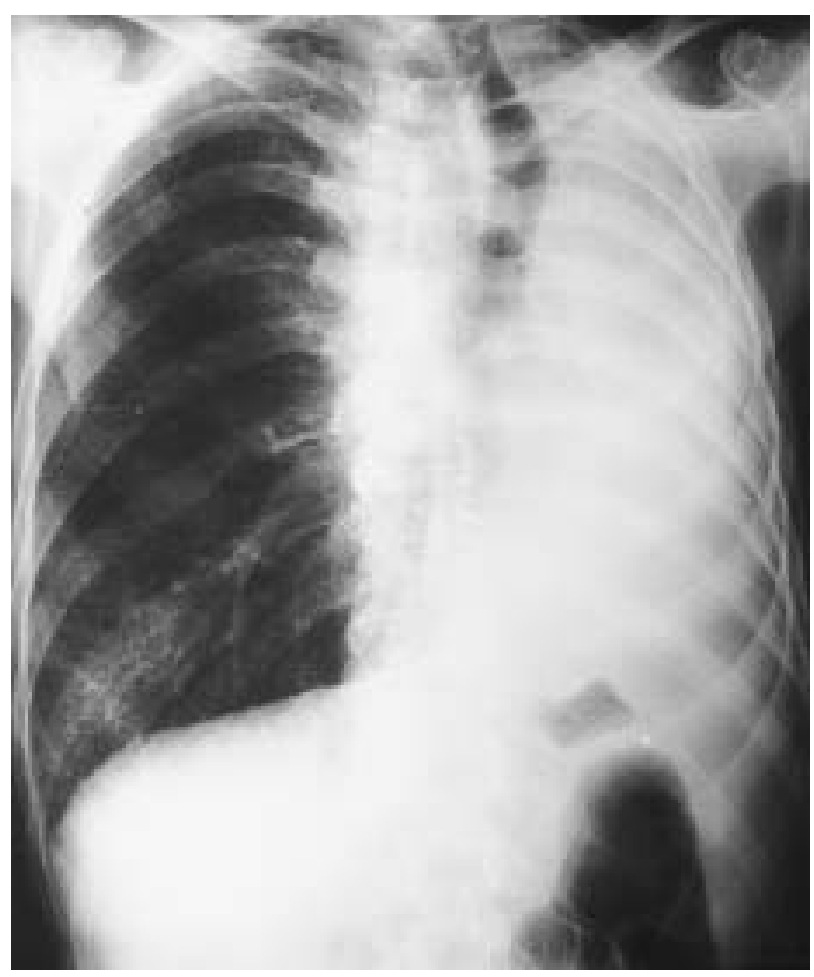

Fig. 1. - Chest radiograph on admission, showing a right basilar infiltrate. 


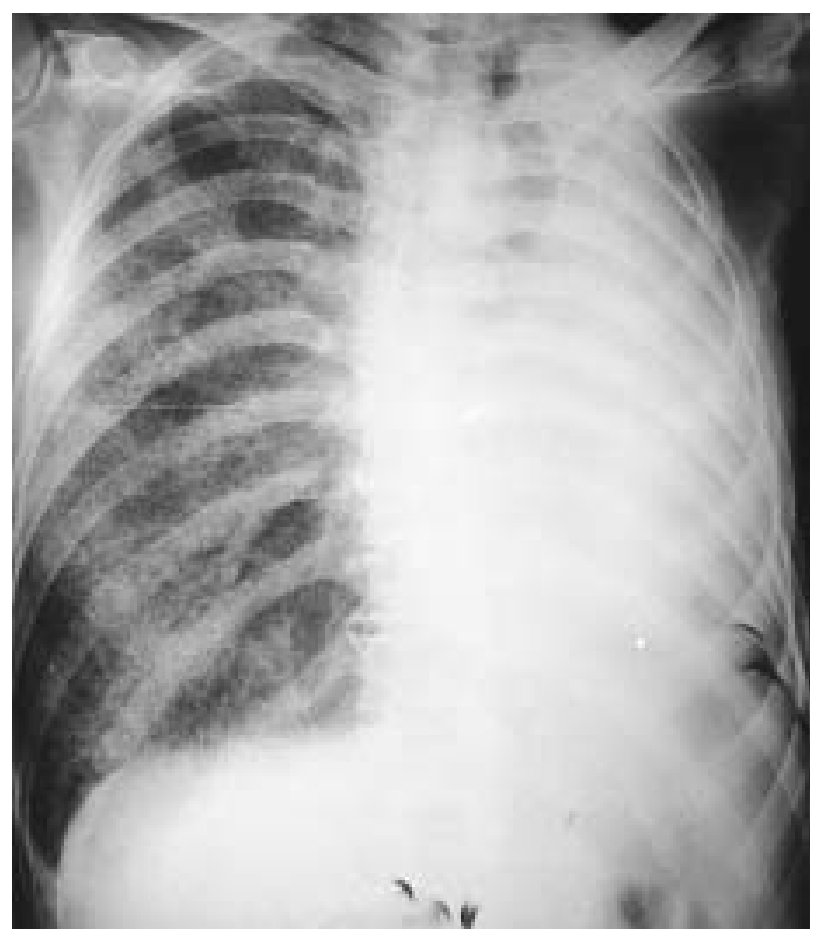

Fig. 2. - Chest radiograph on day 2, showing diffuse alveolar-interstitial infiltrate involving the whole right lung.

cell count (WBC) 5,610 cells $\cdot \mathrm{mm}^{-3}$ with normal differential cell count, haemoglobin $(\mathrm{Hb}) 12.4 \mathrm{~g} \cdot \mathrm{dL}^{-1}$, platelets (PLT) $104.000 /$ platelets $\cdot \mathrm{mm}^{-3}$, glucose $135 \mathrm{mg} \cdot \mathrm{dL}^{-1}$. Lactate dehydrogenase, transaminases, urea, $\mathrm{Na}^{+}, \mathrm{K}^{+}$and $\mathrm{Cl}^{-}$were in the normal range. Blood cultures were negative for aerobic and anaerobic bacteria. Serology for Mycoplasma, Legionella and respiratory viruses was negative. Broad-spectrum antibiotics (ceftazidime $2 \mathrm{~g}$ t.i.d. i.v. and gentamicin $80 \mathrm{mg}$ b.i.d. i.v.) were started, without clinical benefit. Hypoxaemia became refractory to oxygen therapy $\left(\mathrm{Pa}_{\mathrm{a}} \mathrm{O}_{2} /\right.$ inspiratory oxygen fraction $\left.\left(F \mathrm{I}, \mathrm{O}_{2}\right)=103\right)$ fulfilling the criteria for ARDS [7], and nasal continuous positive airway pressure (CPAP) $\left(5 \mathrm{cmH}_{2} \mathrm{O}\right)$ was required to achieve an arterial oxygen saturation $\left(\mathrm{Sa}_{\mathrm{a}} \mathrm{O}_{2}\right)>90 \%$. Chest radiography showed extension of the basilar opacity, involving the whole right lung (fig. 2). Therapy with trimethoprimsulphamethoxazole (5 mg.kg-1 trimethoprim and $25 \mathrm{mg} \cdot \mathrm{kg}^{-1}$ sulphamethoxazole q.i.d. i.v.) and methylprednisolone (2 $\mathrm{g}$ daily $i . v$.) was instituted. There was a clinical worsening, and the patient died 4 days after admission. He had declined mechanical ventilation.

\section{Pathological findings}

At autopsy the right lung appeared heavy and stiff, without macroscopic focal lesions. Light microscopic examination revealed a pattern of $\mathrm{DAD}$, with necrotic lesions of alveolar walls and hyaline membranes (fig. 3); occasional myxomatous organizing buds were seen in alveolar spaces. Rare silicotic nodules were present. Lesion attributable to viral infection or other specific aetiologies were absent. Tissue staining for Mycobacteria, fungi and Pneumocystis carinii were negative, as were tissue cultures for bacteria, Mycobacteria and fungi.

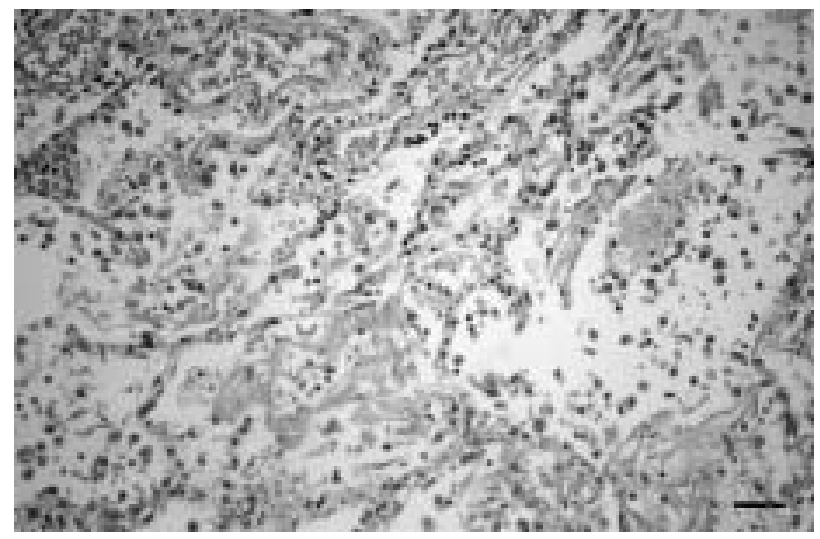

Fig. 3. - Histopathological findings showing diffuse alveolar damage with interstitial oedema and hyaline membranes. Haematoxylin and eosin stain; internal scale bar $=100 \mu \mathrm{m}$.

\section{Discussion}

Many drugs have been related to lung injury with a DAD pattern $[1,8,9]$. The major group consists of antineoplastic agents [10]. The clinical features of lung toxicity are not specific (dyspnoea, cough, fever, pulmonary infiltrates) and the differential diagnosis includes infection, relapse of the underlying disease, pulmonary oedema and changes due to oxygen or radiation $[1,8]$. The pathological findings of drug-related DAD are also quite nonspecific [1] and the diagnosis is one of exclusion. In our case the clinical history and the exclusion of other identifiable inciting factors suggest the antineoplastic drug as the cause of lung injury. The clinical onset and the pathological pattern are consistent with a dose-related toxicity.

Gemcitabine is an analogue of deoxycytidine recently introduced in clinical use $[4,5]$. Unlike cytosine arabinoside (Ara-C), a structurally similar analogue, gemcitabine has significant activity against solid tumours. In all of the NSCLC trials, toxicity was modest, thrombocytopenia and neutropenia being the most frequent toxic effects [5]. Transient dyspnoea, the pathogenesis of which is unknown, has been reported in about $10 \%$ of patients soon after the infusion [5]. In a recent update, gemcitabine was not included among "drugs that may injure the respiratory system" [9]. To our knowledge, seven cases of drug-related pulmonary toxicity termed "lung oedema", have been suspected (Eli Lilly and Co., Clinical Investigator's Brochure, 1995 , with permission), but there was no pathological confirmation. Recently, pulmonary toxicity resulting from treatment with gemcitabine has been described in three patients, two of whom died [13]. Postmortem examination revealed pathological findings consistent with ARDS. In the fatal cases, radiological signs of pulmonary toxicity appeared during cycle 6 and 2, respectively. In one patient, who recovered after withdrawal of gemcitabine (cycle 3 ) with corticosteroids, transbronchial lung biopsy showed nonspecific interstitial pneumonitis.

The similar analogue Ara-C has been associated with noncardiogenic pulmonary oedema $[8,10,12,13]$. In the reported cases, symptoms occurred either while taking the drug, or up to 28 days after cessation of therapy. In a large series, acute respiratory failure developed in 13 of $103(12 \%)$ patients treated with high-dose Ara-C for acute leukae- 
mia. Nine of the patients died; autopsy was performed in seven, and revealed "oedema alone" in six cases and "diffuse alveolar damage" in one case [12].

We conclude that severe respiratory failure with a histological pattern of alveolar damage can develop during treatment with gemcitabine. This requires careful followup of patients treated with this drug.

\section{References}

1. Katzenstein A-L A, Askin FB. Surgical Pathology of Non-Neoplastic Lung Disease. Philadelphia, W.B. Saunders Company, 1990.

2. Olson J, Colby TV, Elliott CG. Hamman-Rich syndrome revisited. Mayo Clin Proc 1990; 65: 1538-1548.

3. Katzenstein AL, Myers JL, Mazur MT. Acute interstitial pneumonia. A clinicopathologic, ultrastructural, and cell kinetic study. Am J Surg Pathol 1986; 10: 256-267.

4. Plunkett W, Huang P, Xu Y-Z, Heinemann V, Grunewald R, Gandhi V. Gemcitabine: metabolism, mechanisms of action and self-potentiation. Semin Oncol 1995; 22 (Suppl. 11): 3-10.

5. Anderson H, Lund B, Bach F, Thatcher N, Walling J, Hansen HH. Single-agent activity of weekly gemcitabine in advanced non-small cell lung cancer: a phase II study. J Clin Oncol 1994; 12: 1821-1826.
6. Hudson LD, Milberg JA, Anardi D, Maunder RJ. Clinical risk for development of the acute respiratory distress syndrome. Am J Respir Crit Care Med 1995, 151: 293-301.

7. Bernard GR, Artigas A, Brigham KL, et al. and the Consensus Committee. The American-European consensus conference on ARDS: definitions, mechanisms, relevant outcomes, and clinical trial coordination. Am J Respir Crit Care Med 1994; 149: 818-824.

8. Rosenow EC III, Myers JL, Swensen SJ, Pisani RJ. Drug-induced pulmonary disease. An update. Chest 1992; 102: 239-250.

9. Foucher P, Biour M, Blayac JP, et al. Drugs that may injure the respiratory system. Eur Respir J 1997; 10: 265-279.

10. Cooper JAD, White DA, Matthay RA. Drug-induced pulmonary disease. Part 1: cytotoxic drugs. Am Rev Respir Dis 1986; 133: 321-340.

11. Pavlakis N, Bell DR, Millward MJ, Levi JA. Fatal pulmonary toxicity resulting from treatment with gemcitabine. Cancer 1997; 80(2): 286-291.

12. Andersson BS, Luna MA, Yee C, Hui KK, Keating ALT, McCredie KB. Fatal pulmonary failure complicating highdose cytosine arabinoside therapy in acute leukemia. Cancer 1990; 65: 1079-1084.

13. Reed CR, Glauser FL. Drug-induced noncardiogenic pulmonary edema. Chest 1991; 100: 1120-1124. 